\title{
Investigating Composting as a Mitigation Strategy for Climate Change Using a Modelling Approach
}

\author{
By Preeya Vijayalakshmee Ramasamy Coolen ${ }^{1}$, Toshima Makoondlall-Chadee ${ }^{1}$, \\ Chandradeo Bokhoree ${ }^{1}$, Ravi Foogooa ${ }^{2}$
}

\begin{abstract}
The waste management sector accounts for $19 \%$ of greenhouse gases produced by the island of Mauritius, and is second to the energy sector which contributes about $77 \%$ of total emissions. Significant mitigating measures are being sought to reduce the impact of the waste sector. The main greenhouse gas produced from waste in Mauritius is methane from landfill disposal. Among the different alternate waste management scenarios proposed, home composting is one strategy to achieve carbon reductions in the sector. However, this target can only be achieved if the composting process is properly controlled. Objectively, a lumped parameter model was used to analyse the set of variation parameters to achieve greatest reduction in methane through optimal composting. The composting matrix was modelled as a point source. Mass balance equations were coupled with heat transport equations and reaction kinetics equations to determine the optimal set of parameters for efficient composting of yard waste and kitchen waste. The simulations demonstrated that bulking of vegetable waste prior to composting is required to prevent production of methane.
\end{abstract}

Keywords: composting, lumped parameter model, climate change mitigation

\section{Introduction}

Composting can be defined as the natural biological degradation of organic matter by micro-organisms, in the presence of oxygen, to form a stable and sanitised product known as compost (Anepu, 2012). Carbon dioxide and water are the by-products of this exothermic process. Interest in the process in the past was mainly due to the agricultural benefits of the compost produced (Białobrzewski et al, 2015). Compost is an excellent soil conditioner. It increases the water holding capacity of the soil, thus preventing soil erosion and nutrient run-off. Humus increases the soil's content in organic matter. It is also a natural source of nutrients for plants, and therefore reduces the need for fertilizers (Wei et al, 2017). The high temperatures attained during composting can be used to destroy weed seeds and harmful pathogens in plants, potentially reducing the need for herbicides and pesticides (Kaushal et al,2012)).

The organic fraction of municipal solid waste ranges from about twenty percent in developed countries to up to seventy five percent in developing countries (OECD, 2007, Rastogi et a.,2019) and prediction models forecast an escalation in the production of food waste (Adhikari et al, 2006). Composting, anaerobic digestion, thermal treatment and landfill disposal are some of the different possible options for organic waste treatment (Silva et al, 2007). Life cycle assessment combined with worth benefit analysis has 
demonstrated that composting is a better option for organic waste recycling than thermal treatment (Skordilis, 2009). Composting has also been shown to reduce greenhouse gas emissions since only carbon dioxide gas is produced as by-product and when applied to soil temporarily sequestrates some carbon (Amlinger et al, 2008; Favoino and Hogg, 2008, Bokhoree \& Kisnah, 2010). It is also well known that composting is accompanied by volume reductions of up to $60 \%$ (Hwang et a., 2002; Yaghmaein et al, 2005, Onwosi et al, 2017). Composting is therefore considered as a sustainable organic waste management solution (Najm et al, 2002; Eriksson et al, 2002; Klang et al, 2006).

Composting is the process through which micro-organisms such as bacteria, fungi, yeasts and actinomycetes naturally convert, in the presence of oxygen, organic matter into carbon dioxide, water and a stable product called compost (Tchobanoglous et al, 1993, LopezGomes et al, 2019)). The process is exothermic, where thermal energy is another byproduct. There are numerous parameters and properties such as temperature, moisture, free air space, aeration rate, particle size and biodegradability influencing the composting process and the quality of the end-product, the compost.

Temperature is a key parameter in the composting process and at the same time it is a function of the process (Epstein, 1997). It has a direct impact on the species of microorganisms present in the substrate by affecting their rate of reaction and the moisture content. The Arrhenius equation which expresses the mathematical relationship between temperature and rate of reaction based on theoretical and experimental observations is assumed to hold for biological processes (Bari et al., 2000). An increase in temperature creates a positive feedback on the reaction rate, thus inducing a cumulative temperature rise. This generation and accumulation of heat energy also affects the moisture content of the compost, and thus, the rate of reaction indirectly also (Epstein, 1997, Mohee, 1998). The temperature can be controlled through the aeration rate. Increasing the airflow through the system increases the rate of evaporation which causes a cooling effect (Guo et al, 2020).

The reactions kinetics of composting are affected by moisture content through changes in oxygen availability, water potential and microbial growth rates (Richard et al., 2002). Moisture is present in the system within the substrate. Additionally, moisture is added to the system by decomposition of organic matter and removed through evaporation (Epstein, 1997). Moisture is essential for the composting process since water is required to dissolve the nutrients in the organic matter to make it available to the micro-organisms. It also acts as a medium for gas exchange and microbial migration. Biological activity almost stops at moisture levels below 20\% (Haug, 1993, Robinson \& Stentiford, 1993). However moisture contents above $70 \%$ also hinder the composting process. This is because at these high levels of moisture, the pores get clogged. Free air space is reduced to practically zero and diffusion of gases is severely hindered. The optimum moisture content of a starting substrate mix is usually given to be between $50 \%$ and $70 \%$. This however may vary, depending on the structure of the substrate. Materials with good structural strength support higher moisture levels since their porosity and therefore their free air space are not affected. Substrates that tend to collapse during composting may however require lower moisture content since porosity will decrease and the material will tend to compact, thus preventing gas diffusion.

Moisture content can be adjusted at the start of the composting process by adding a 
bulking agent having at low moisture content to a wet substrate. Consequently, water or liquid waste can used to condition dry substrates. Increasing aeration rate is another method to lower moisture content during the process, by increasing evaporation. Composting is usually known as a drying process, implying that moisture usually decreases as the substrate degrades (Kulcu and Yaldiz, 2005). If the starting moisture level is too high however, the inverse may occur, and leachate may even be formed (Oazana et al, 2018).

The compost matrix consists of solid organic particles surrounded by empty spaces. It can be considered as a porous medium. Free air space is essential during composting for air diffusion so that oxygen is made available to the micro-organisms for aerobic decomposition. Poulsen and Moldrup (2006) observed that there was a direct relationship between $\log$ of porosity and $\log$ of air permeability. Field work has shown that a free air space ratio of about 0.3 is optimum (Jeris \& Regan, 1973, Schultz, 1962). Moisture and free air space are inversely related and since both are important to the process, a trade-off is required (Sundberg, 2003).

Porosity depends on the structure and particle size of the material. The larger the particles, the larger will be the pores. If the porosity of a starting substrate is too low, it can be increased by mixing it with a bulking agent. Wood chips are often used for this purpose. Conversely, a substrate which is too porous can be shredded and compacted to reduce its porosity. Since composting is accompanied by a reduction in particle size, porosity tends to decrease during the process (Mohee et al., 2008).

The principal role of aeration during composting is to supply micro-organisms with oxygen for their survival and to break down organic matter. Aeration however also removes heat from the system, and water in the form of water vapour and can therefore be used as a control method for temperature and moisture (Calabi-Floody et al, 2019). Although the maximum total amount of oxygen required to completely oxidise the substrate can be estimated from its chemical composition, the rate at which the oxygen needs to be supplied is very difficult to determine, as it is a function of the porosity of the material and the rate of reaction, which in turn is a function of numerous parameters (Chang et al, 2019). Haug (1993) was however able to observe that the aeration rate needed for temperature control or for drying usually exceeded the aeration requirements for the bio-chemical reactions.

Substrate biodegradability is the fraction of the initial mass that would degrade under composting conditions. It is used to determine the amount of heat energy generated during the process, as well as the actual oxygen demand. The biodegradability coefficient is the ratio of the amount of substrate decomposed to the total amount of substrate. This value is usually determined experimentally, from respirometric studies or from mass balance equation. The biodegradability of a substrate depends on its chemical composition. Lipids, sugars and hemi-cellulose degrade quite easily (Hwang et al., 2002), proteins and fats being less susceptible (Nakasaki et al., 2004) and with lignin being the most resistant to decomposition. Studies have showed that the lignin content of a material is the predominant factor in determining the biodegradability.

Proper control of these process parameters ensures that composting occurs effectively. It is important to ensure that aerobic conditions are maintained throughout the process to prevent the production of methane. Moisture content is an essential parameter which 
impacts on the absorption transport of oxygen. A saturated substrate with moisture content greater than $70 \%$ hinders movement of gas and limits the supply of oxygen to micro-organisms. On the other hand, moisture dissolves oxygen to make it available to microorganisms and therefore it is recommended that the moisture content of a compost mix be at least 20\% (Haug, 1993). The purpose of this paper is to determine the ideal mix of household organic waste to ensure aerobic decomposition and prevent the emission of methane.

\section{Material and Methods}

A lumped parameter model of reactor composting as developed by Ramasamy et al. (2008) was used. The model considered a first order reaction kinetics where rate functions, mass balance, water balance, gas balance and thermal balance equations were considered to predict the temporal changes in temperature, moisture content and mass decrease of the substrate. The variables of the models were ambient temperature, initial moisture content of the substrate, the air flow ratthe relative humidity of air, the biodegrable fraction of substrate, the initial mass of the substrate and the dimensions and material of the reactor.

The first order kinetic equation in the form of equation 1 was used since its effectiveness and accuracy have been proven (Smith and Eilers, 1980; Haug,1993; Marugg et al., 1993, Keener et al., 1993; Das and Keener, 1997; Mohee et al., 1998, Hamoda et al., 1998, Higgins and Walker, 2001; Scholwin and Bidlingmaier, 2003, Komilis, 2006, Soobratee et al., 2007, Sole-Mauri et al., 2007, Ramasamy \& Bokhoree, 2009).

$\frac{d m_{s}(t)}{d t}=-k\left(m_{s}(t)-m_{f}\right)$

Where, $\mathrm{m}_{\mathrm{s}}(\mathrm{t})$ is the mass of substrate at time, $\mathrm{t}, \mathrm{kg}$

$\frac{d m_{s}(t)}{d t}$ is the rate of substrate degradation with respect to time, kgday $^{-1}$

$\mathrm{k}$ is the rate function and is dependent on temperature and moisture content, day ${ }^{-1}$

$\mathrm{m}_{\mathrm{f}}$ is the final mass of substrate, $\mathrm{kg}$.

The rate equation was expressed as a function of temperature, moisture content and free air space and it was assumed that oxygen concentration is not a limiting factor.

The temperature rate coefficient adapted from the Arrhenius equation and given by equations 2, 3 and 4 below were used. The values for the variables were determined from data obtained in literature.

$$
\begin{aligned}
& \text { when } T<T_{m}: k_{T}=\exp \left\{-\frac{E_{a}}{R_{a}}\left(\frac{1}{T+273}-\frac{1}{T_{S}+273}\right)\right\} \\
& \text { when } T_{m} \leq T \leq T_{L}: k_{T}=\frac{T_{L}-T}{T_{L}-T_{m}}
\end{aligned}
$$

Where, $\mathrm{T}_{\mathrm{s}}$ is the preference temperature, ${ }^{\circ} \mathrm{C}$

$\mathrm{T}_{\mathrm{m}}$ is the medium threshold temperature, ${ }^{\circ} \mathrm{C}$

$\mathrm{T}$ is the temperature of the composting bulk, ${ }^{\circ} \mathrm{C}$

$\mathrm{T}_{\mathrm{L}}$ is the maximum allowable temperature for microbial activities, ${ }^{\circ} \mathrm{C}$

$\mathrm{E}_{\mathrm{A}}$ is the activation energy of composting bulk, $\mathrm{Jmol}^{-1}$

$\mathrm{R}$ is the universal gas constant Jmole-1 $\mathrm{K}^{-1}$ 
The moisture content rate coefficient was derived by Smith and Eilers (1980) and adapted by Mohee et al. (1998) and is given by the equation 5 .

$k_{m_{c}}=-56.97+57.98 e^{\left(\frac{-0.5\left(m_{c}-0.56\right)}{1.52}\right)^{2}}$

The gas balance equation used is given in equation 6 .

$\frac{d m_{d r y_{\text {exhaust }}}}{d t}=\frac{d m_{d r y_{\text {air }}}}{d t}+\frac{d m_{s}}{d t}\left(x_{\mathrm{CO}_{2}}-x_{\mathrm{O}_{2}}\right)$

The masses of carbon dioxide formed and oxygen used per day are determined from the rate of reaction, $\frac{d m_{s}}{d t}\left(\frac{\mathrm{kg}}{d a y}\right)$ and the fractional amounts of gases that are formed and depleted respectively per unit mass of substrate decomposed. $x_{\mathrm{CO}_{2}}$, the mass of carbon dioxide gas produced per mass of substrate decomposed during the reaction and $x_{\mathrm{O}_{2}}$, the mass of oxygen gas absorbed per mass of substrate decomposed during the reaction were in turn calculated from the stoichiometric equation of the oxidation of the substrate which is given by the formula below (Haug, 1993), using equations 8 and 9 .

$$
\begin{array}{lr}
\mathrm{C}_{a} \mathrm{H}_{b} \mathrm{O}_{c} \mathrm{~N}_{d}+\frac{2 a+(b-3 d)}{2(2-c)} \mathrm{O}_{2} \rightarrow a \mathrm{CO}_{2}+\frac{b-3 d}{2} \mathrm{H}_{2} \mathrm{O}+d \mathrm{NH}_{3} & \ldots \text { (Eq. 7) } \\
x_{\mathrm{CO}_{2}}=\frac{44 a}{\text { MolecularMassofsubstrate }} & \ldots \text { (Eq. 8) } \\
x_{\mathrm{O}_{2}}=\frac{32\{2 a+(b-3 d)\}}{2(2-c) \times \text { MolecularMassofsubstrate }} & \ldots \text { (Eq. 9) }
\end{array}
$$

The flow rate was calculated as a function of the pressure difference between the inlet and the outlet, using equation 10.

$Q=C_{d} A\left(\frac{2 \Delta P}{\rho}\right)^{\frac{1}{2}}$

Where, $\mathrm{Q}$ is the volumetric air flow rate, $\mathrm{m}^{3} \mathrm{~s}^{-1}$

$\mathrm{C}_{\mathrm{d}}$ is the discharge coefficient $(=0.65$ for clear orifices)

$\mathrm{A}$ is the area of the opening, $\mathrm{m}^{2}$

$\Delta \mathrm{p}$ is the pressure difference between the inlet and the outlet, $\mathrm{Pa}$

$\varrho$ is the density of air, $\mathrm{kgm}^{-3}$

The water balance equation expressed the changes in the water content of the system and is given by equation 11. During the composting process, water is formed as a by-product. The rate of formation of water is a function of the rate of decay, $\frac{d m_{s}}{d t}\left(\frac{\mathrm{kg}}{d a y}\right)$, and the amount of water generated per unit mass of waste decomposed, $x_{\mathrm{H}_{2} \mathrm{O}}$.

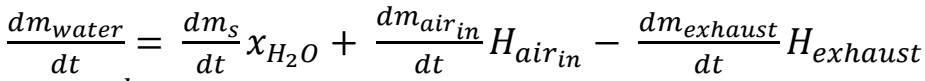

Where, $\frac{d m_{\text {water }}}{d t}$ is the rate of change of the mass of water in the substrate matrix, kgday ${ }^{-1}$ $\frac{d m_{\text {air }}}{d t}$ is the mass air flow rate of incoming air, $\mathrm{kgday}^{-1}$

$\frac{d m_{\text {exhaust }}}{d t}$ is the mass air flow rate of the exhaust gases, kgday $^{-1}$

$\mathrm{H}$ is the specific humidity of air, $\mathrm{kg}_{\text {water }} / \mathrm{kg}_{\text {dryair }}$

The moisture entering the system with incoming air and the moisture leaving the system with the vapour saturated exhaust air are derived from the respective mass flow rates and specific humidity. Specific humidity of air was calculated using ASAE standard Psychometric Data and the Goff-Gratch equation for saturated vapour pressure. 
The energy stored in the system causes the sensible heating of the substrate matrix and is used to calculate the rate of change of temperature with time using equation 12 .

$\frac{d E_{\text {stored }}}{d t}=\left(\left(m_{\text {substrate }} c_{\text {substrate }}\right)+\left(m_{\text {water }} c_{\text {water }}\right)+\left(m_{\text {air }} c_{\text {air }}\right)\right\} \frac{d T}{d t} \quad \ldots$ (Eq. 12)

Where, $\frac{d E_{\text {stored }}}{d t}$ is the rate of change of energy stored in the system, $\mathrm{Jday}^{-1}$ and

$\mathrm{m}$ is the total mass, $\mathrm{kg}$

$\mathrm{c}$ is the specific heat capacity, $\mathrm{Jkg}^{-1} \mathrm{~K}^{-1}$

The equation derived by Mears et al. (1975) was used to determine the specific heat capacity of the matrix, depending on its moisture content.

The rate of energy generated as a result of microbial activity was expressed as the product of the rate of decomposition and the enthalpy of the substrate. In the absence of experimental data, heat of combustion was taken as an approximate value for the enthalpy, although it is invariably higher, since not all of the available energy is released during decomposition.

Most of the energy lost is assumed to be in the form of vaporisation of a percentage of the water formed during the process and conductive losses through the reactor walls. Convective losses and heat loss due to radiation are negligible since the process occurs within an enclosed space.

In a lumped parameter model, the substrate is assumed to be a point source with no spatial variations in the model variables. Effective stress due to loading was therefore assumed to be equal to zero. Settlement was modeled as being a function of only two parameters, namely the mass of substrate and the bulk density of the substrate, as given by equation 13.

$\frac{d V}{d t}=\frac{d m(t)}{d t} \times \rho(t)$

Where, $\mathrm{V}$ is the volume of substrate, $\mathrm{m}^{3}$

$\rho$ is the bulk density of the substrate, $\mathrm{kgm}^{-3}$

The rate of change of mass of solid is determined from the reaction kinetics. The water balance equation is used to determine the change in moisture content of the substrate. The change in mass and change in volume are used to compute the bulk density of the substrate.

\section{Results and Discussion}

In this paper, the optimum conditions for composting of kitchen waste were determined using the above described model. Kitchen waste has an initial moisture content ranging between $80 \%$ and $95 \%$ (Briski et al., 2006, Chang et al., 2006). A bulking agent was used to bring the moisture content within the range optimal range of $20-70 \%$. Yard waste, another organic fraction of municipal solid waste has been considered as a bulking agent since it has a relatively lower moisture content, ranging between $30 \%$ and $45 \%$ (Manu et al, 2013, Hla \& Roberts, 2015). Simulations were run for different mixes assuming an average initial moisture content of $90 \%$ and $35 \%$ for kitchen waste and yard waste respectively. The initial conditions of ambient temperature, total volume of waste, reactor volume and surface area were kept constant at $23^{\circ} \mathrm{C}, 200 \mathrm{~kg}, 1 \mathrm{~m}^{3}$ and $6 \mathrm{~m}^{2}$ respectively. The variation of moisture content and temperature during the process were 
observed over a period of 25 days to investigate the optimal mixture which would ensure aerobic conditions throughout.

Table 1: Initial parameters for composting of kitchen waste and garden waste

\begin{tabular}{|l|c|c|c|c|}
\hline Parameter & Mix 1 & Mix 2 & Mix 3 & Mix 4 \\
\hline Ratio kitchen waste: yard waste & $1: 1$ & $1: 2$ & $1: 3$ & $1: 5$ \\
\hline Initial moisture content, \% & 62.5 & 53.3 & 48.8 & 44.2 \\
\hline
\end{tabular}

The results showed that in all four cases, the moisture content of the composting pile remained within the recommended range of $20-70 \%$ (Haug, 1993). The process has therefore been continuous and anaerobic conditions have been avoided. In scenario 1 which contained equal masses of kitchen and garden waste, the moisture content of the mix increased from day 1 to reach a maximum value of $66.22 \%$ on day 16 . The moisture content decreased steadily from day 17 to day 25. This is equivalent to a net increase of $4.5 \%$. The same trend was observed during the three other simulations. Scenarios 2,3 and 4 however observed sharper increases in the moisture content within the initial 15 days of the process. Maximum values of moisture contents were $64.95 \%$ on day 12 for mixture $2,62.1 \%$ on day 8 for mixture 3 and $56.7 \%$ on day 8 for mixture 4 . The mixture of $20 \%$ kitchen waste and $80 \%$ garden waste, i.e., mix 4 underwent the greatest increase in overall moisture content, from an initial value of $44.2 \%$ to a value of $50.85 \%$ at the end of the 25-day period. The initial increase in moisture content can be explained from the high initial reaction rate due to the presence of readily digestible organic matter such as sugars, carbohydrates and proteins. During this period, the rate at which water is produced from decomposition is greater than the rate at which it is removed from the mix by the process of evaporation. As temperatures decrease over the subsequent days, decomposition slows down. The rate of loss of water exceeds the rate of water formation, leading to drying. The rate of evaporation during that period is however not sufficient to remove the net mass of water produced over the 25 days such that there is a net increase in moisture content in the four scenarios.

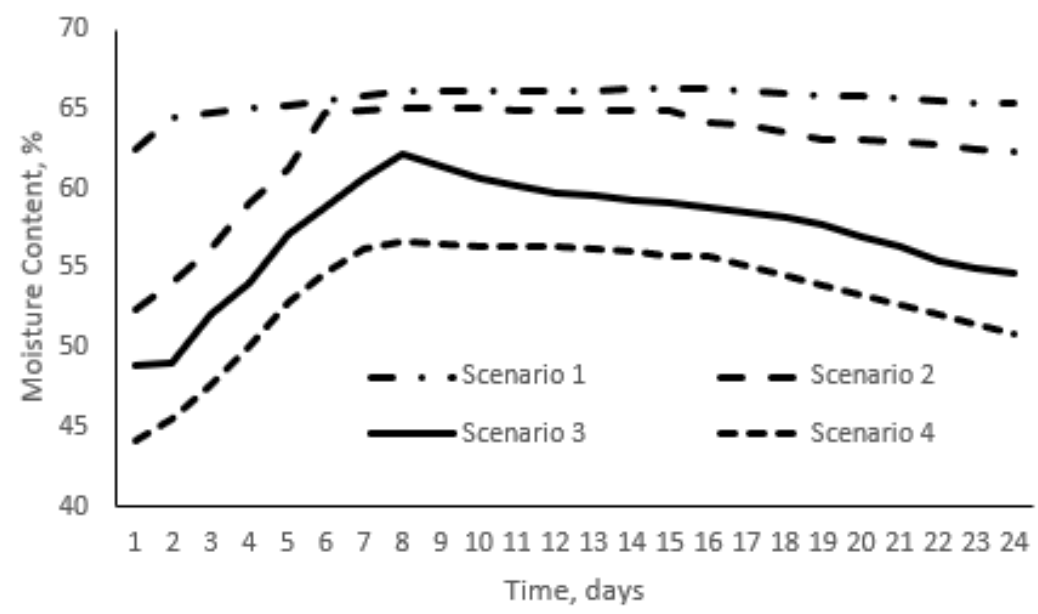

Figure 1: Variations in moisture content during the process 
Table 2: Maximum values and net change in moisture content during the process

\begin{tabular}{|l|c|c|c|c|}
\hline & Mix 1 & Mix 2 & Mix 3 & Mix 4 \\
\hline Maximum moisture content reached, \% & 66.22 & 64.95 & 62.1 & 56.7 \\
\hline Net change in moisture content, \% & 4.64 & 15.05 & 11.89 & 19.12 \\
\hline
\end{tabular}

Richard et al. (2002) and Xi et al (2005) however both observed overall decreases in moisture content during composting, confirming that composting is a drying process (Kulcu \& Yaldiz, 2005). The difference in simulations in the present case may be due to differences in initial parameters used in the model, such as ambient conditions of temperature and humidity, aeration rates and reactor characteristics. All these parameters affect the rate of water loss due to evaporation and will therefore have a direct impact on the moisture content of the compost pile.

The temperature profiles of all four simulations follow the trend on a sharp increase in temperature during the initial 3 days followed by a sharp decrease during the next 7 days. The temperature constantly decreases at a slower rate as from day 10 . The maximum temperatures observed are $67^{\circ} \mathrm{C}$ on day 4 for mixture $1,62.4^{\circ} \mathrm{C}$ on day 4 for mixture 2 , $56^{\circ} \mathrm{C}$ on day 2 for mixture 3 and $54.5^{\circ} \mathrm{C}$ on day 4 for mixture 4 . Temperatures greater than $45^{\circ} \mathrm{C}$ are observed during 7 days, from day 2 to day 8 in scenario 1,4 days form day 2 to day 5 in scenario 2, 5 days from day 2 to day 6 in scenario 3 and 4 days from day 3 to day 6 in scenario 4 . The sharp initial increase in temperature is explained by the fast decomposition of readily digestible nutrients at the start of the process. The process being exothermic and the rate of decomposition being a function of temperature, a positive feedback is created thereby a fast temperature rise is observed. As the reaction increases however, the mass of water produced also increases producing a cooling effect. A sharp decrease in temperature is therefore observed as from day 4 , which is equivalent to a decrease in the rate of decomposition. Water having a high specific heat capacity experiences smaller temperature changes for the same amount of heat energy absorbed as compared to dry solids. Bari et al. (2000), Mohee et al. (2008), Seki \& Shijuku (2012) also observed similar trends whereby the temperature reached a maximum value within the first five days to gradually decrease.

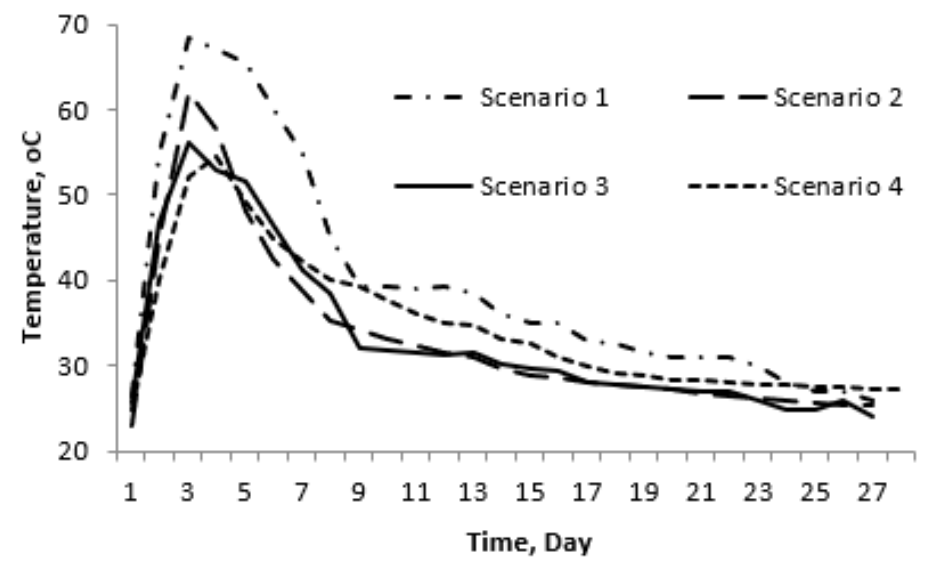

Figure 2: Variations in temperature during the process 
Table 3: Maximum temperatures and duration of thermophilic phase during the process

\begin{tabular}{|l|c|c|c|c|}
\hline & Mix 1 & Mix 2 & Mix 3 & Mix 4 \\
\hline Maximum temperature reached, ${ }^{\circ} \mathrm{C}$ & 67 & 62.4 & 56 & 54.5 \\
\hline Number of days temperature $>45^{\circ} \mathrm{C}$ & 7 & 4 & 5 & 4 \\
\hline
\end{tabular}

Corelating temperature and moisture content profiles demonstrates that greatest temperatures are observed in scenario 1 . This indicates that decomposition was fastest and more efficient in scenario 1, where the initial moisture content was highest at $62.5 \%$. Horisawa et al. (2000) also observed that microbial activity was highest at moisture contents above $60 \%$. A direct relationship can also be observed between initial moisture content and highest temperatures reached. The mix with the highest initial moisture content which is mix 1 recorded the highest maximum temperature and the mix with the lowest initial moisture content, which is mix 3 recorded the lowest maximum temperature. This indicates that it is important to adjust the moisture content at the start of the process itself, as confirmed by Richard et al. (2000).

\section{Conclusion}

Composting, especially home composting is considered as a sustainable solution to organic waste management. Indeed, it promotes the proximity principle and has very little environmental impacts. Additionally, the produced compost is a sanitised product which can be applied to soil as a soil conditioner or as an organic fertiliser. Composting has lately also been considered as a climate mitigation solution for the waste management sector due to the fact that only carbon dioxide is produced as emissions. Comparatively, landfill, aerobic decomposition, incineration produce greenhouse gases such as methane and nitrous oxides which have higher global warming potentials. Application of compost to land also serves as a carbon capture strategy through sequestration. For the composting process to be efficient, excess supply of oxygen is required to ensure aerobic conditions. In the absence of oxygen, the process to turn into anaerobic decomposition, leading to the production of methane. It is therefore important to ensure that all parameters are properly controlled to prevent these conditions. This paper aimed at investigating the optimal initial moisture content of household organic waste to ensure that transport of oxygen through the compost maintains aerobic conditions. Kitchen waste has high moisture content of upto $95 \%$ and must therefore be mixed with a bulking agent to adjust the initial moisture content. Garden waste, the other fraction of organic household waste was considered as a bulking agent due to its relatively lower moisture content. Four different mixes were considered. The lumped parameter model developed by Ramasamy et al. (2008) was used to simulate composting of the different mixes. The results showed that moisture content remained within the range that will allow composting to occur throughout the process in all four cases. Highest temperatures were however reached during composting of mix 1. It can therefore be concluded form the findings of the paper that a mix of equal parts kitchen waste and garden waste will lead an optimised composting process. 


\section{References}

Adhikari B., Barrington S. \& Martinez J., (2006). Predicted growth of world urban food waste and methane production. Waste Management and Research. Vol. 24, 21-433.

Amlinger F., Peyr S. and Cuhis C.(2008). Green house gas emissions from composting and mechanical biological treatment. Waste Management and Research. Vol. 26, 47-60.

Annepu R.K.(2012). Sustainable Solid Waste Management in India, 2. Columbia University, New York

Bari Q. H., Koenig A. \& Guihe T.(2000). Kinetic analysis of forced aeration composting - I. Reaction rates and temperature. Waste Management and Research. Vol. 18, 303-312.

Białobrzewski I., Mikš-Krajnik M., Dach J., Markowski M, Czekała W. \& Głuchowska K. (2015). Model of the sewage sludge-straw composting process integrating different heat generation capacities of mesophilic and thermophilic microorganisms. Waste Management. 43 , 72-83.

Briski F., Vukovic M., Papa K., Gomzi Z. \& Domanovac T., Modeling of composting food waste in a column reactor, 33rd International Conference of the Slovak Society of Chemical Engineering, 2006

Bokhoree C. \& Kishnah S.(2010). Towards achieving a green composting system for organic waste treatment: a modelling approach. International Journal of Climate Change: Impacts and Responses. Vol. 2(1), 173-194.

Calabi-Floody M., Medina J., Suazo J., Ordiqueo M., Aponte H., de La Luz Mora M. \& Rumpel C.(2019). Optimization of wheat straw co-composting for carrier material development. Waste Management. 98, $37-49$.

Chang J. I., Tsai J. J. \& Wu K. H., Composting of vegetable waste, Waste Management and Research, Vol. 24, Pages 354-362, 2006

Chang, R., Li Y., Chen Q., Guo Q \& Jia J.(2019). Comparing the effects of three in situ methods on nitrogen loss control, temperature dynamics and maturity during composting of agricultural wastes with a stage of temperatures over 70॰ C., Journal of Environmental Management. 230, 119-127.

Epstein E.(1997) The Science of Composting. Technomic Publisbing Company, USA.

Eriksson O., Carsson Reich M., Frostell B., Bjorklund A., Assefa G., Sundqvist J. O., Granath J., Baky A. \& Thyselius L.(2005). Municipal solid waste management from a systems perspective. Journal of Cleaner Production. Vol. 13, 241, 252.

Favoino E. \& Hogg D.(2008). The potential role of compost in reducing greenhouse gases. Waste Management and Research. Vol. 26, 61-69.

Guo Y., Rene E.R., Wang J. \& Ma W.(2020). Biodegradation of polyaromatic hydrocarbons and the influence of environmental factors during the co-composting of sewage sludge and green forest waste. Bioresource Technology. 297, 122434.

Haug R. T.(1993). The Practical Handbook of compost engineering. Lewis Publications, Boca Raton.

Hla SS. \& Roberts D.(2015). Characterisation of chemical composition and energy content of green waste and municipal solid waste from Greater Brisbane, Australia. Waste Management. Jul;41:12-9. doi: 10.1016/j.wasman.2015.03.039. Epub 2015 Apr 13. PMID: 25882791.

Horisawa S, Tamai Y, Sakuma Y, Doi S \& Terazawa M. (2000). Effect of moisture content of a wood matrix on a smallscale biodegradation systemfor organic solid waste. J Wood Sci. 46:317-21.

Hwang E., Shin H. \& Tay J.(2002). Continuous feed, on-site composting of kitchen garbage. Waste Management and Research. Vol. 20, 119-126.

Jeris J. S. \& Regan R. W.(1973). Controlling environmental parameters for optimum composting, Part II: Moisture, free air space and recycle. Compost Science.

Kaushal R.K., Varghese G.K., Chabukdhara M.(2012). Municipal solid waste management in India-current state and future challenges: a review. Int. J. Eng. Sci. Technol. 4 (4) (2012), 1473-1489.

Klang A., Vikman P. A. \& Brattebo H.(2006). Systems analysis as a support for decision making towards sustainable municipal waste management - a case study. Waste Management and Research. Vol. 24(4), 323-331.

Kulcu R. \& Yaldiz O.(2005). Composting dynamics and optimum mixture ratio of chicken manure and vineyard wastes. Waste Management and Research. Vol. 23, 101-104.

Manu M. Rakesh K. \& Anurag G. (2013). Physical and chemical characterization of yard waste. International Journal of Applied Engineering Research. Vol 16(6), 1891-1896.

Mohee R., Mudhoo A. \& Unmar G. D.(2008). Windrow co-composting of shredded office paper and broiler litter. International Journal of Environment and Waste Management. Vol 2(1/2), 3-23. 
Mohee R., White R. K. \& Das K. C.(1998). Simulation model for composting cellulosic (bagasse) substrates. Compost Science \& Utilization. Vol. 6(2), 82-92.

Najm M. A., El-Fadel M., Ayoub G., El-Taha M. \& Al-Awar F.(2002). An optimization model for regional integrated solid waste management II. Model application and sensitivity analyses. Waste Management and Research. Vol. 20, 46-54.

Nakasaki K., Nagasaki K. \& Ariga O.(2004). Degradation of fats during thermophilic composting of organic waste. Waste Management and Research. Vol. 22, 276-281.

Oazana S.H., Naor. M., Grinshpun J., Halachmi L., Raviv M., Saadi I., Avidov R., Sudharsan Varma, Rosenfeld L., Gross A. \& Laor Y.(2018). A flexible control system designed for lab-scale simulations and optimization of composting processes. Waste Management. 72, 150-160.

Onwosi C.O., Igbokwe V.C., Odimba J.N., Eke I.E., Nwankwoala M.O., Iroh I.N., Ezeogu L.I. (2017). Composting technology in waste stabilization: on the methods, challenges and future prospects. Journal of Environmental Management. 190, 140-157.

Poulsen T. \& Moldrup P.(2007). Air permeability of compost as related to bulk density and volumetric air content. Waste Management and Research. Vol. 25, 343-350.

Ramasamy P., Bokhoree C., Mohee R. \& Jamnejad G.(2008). A lumped parameter model of closed system Composting. 23rd International Conference on Solid Waste Technology and Management. Widener University, Philadelphia, USA

Ramasamy P. \& Bokhoree C.(2009). Robust Numerical Windrow System Simulation for Decomposition of Organic Waste, 2008 World Congress in Computer Science Computer Engineering and Applied Computing. Las Vegas, Nevada, USA.

Rastogi M., Nandal M. \& Nain L., (2019). Additive effect of cow dung slurry and cellulolytic bacterial inoculation on humic fractions during composting of municipal solid waste. Int. J. Recycl. Org. Waste Agric. 1-8.

Richard T. L., Hamelers H. V. M., Veeken A. \& Silva T.(2002). Moisture relationships in composting processes. Compost Science \& Utilization. Vol. 10(4), 286-302.

Robinson J. J. \& Stentiford E. I.(1993). Improving the aerated static pile composting method by the incorporation of moisture control. Compost Science \& Utilization. Premier issue, 36-58.

Schultz K. L.(1972). Continuous thermophilic composting. Compost Science.

Silva M. T. B., Menduna A. M. Seijo Y. C. \& Viqueira F. D., (2007). Assessment of municipal solid waste compost quality using standardized methods before preparation of plant growth media. Waste Management and Research. Vol. 25, 99-108.

Skordilis A.(2004). Modelling of integrated solid waste management systems in an island. Resources Conservation \& Recycling. Vol. 41, 243-254.

Sundberg C.(2003). Food waste composting - effects of heat, acids and size. Licentiate Thesis, Swedish University of Agricultural Sciences.

Tchobanoglous G. et al.(1993). Integrated solid waste management - Engineering principles and management issues. MCGraw-Hill, New York et al.

Wei Y., Li J., Shi D., Liu G., Zhao Y. \& Shimaoka T. (2017). Environmental challenges impeding the composting of biodegradable municipal solid waste: a critical review., Resour. Conserv. Recycl.. 122, 5165.

Xi B., Wei Z. \& Liu H., (2005). Dynamic simulation for domestic solid waste composting processes. The Journal of American Science. Vol. 1(1), 35-35.

Yaghmaein K., Malakootian M. \& Noorisepehr M.(2005). Comparison between windrow and pit composting of poultry wastes, leaves and garbage of municipal solid waste in Damghan, Iran. Iranian Journal of Environmental Health and Science Engineering. Vol. 2910, 22-27. 